\title{
Liver $X$ receptor inhibits the growth of hepatocellular carcinoma cells via regulating HULC/miR-134-5p/FOXM1 axis
}

Yan Zhang ( $\sim$ tmmubiozy@163.com )

College of Basic Medical Sciences, Army Medical University

Jintao He

Rocket Force Medicine, College of Preventive Medicine, Army Medical University

Teng Yang

College of Basic Medical Sciences, Army Medical University

Wenhui He

College of Basic Medical Sciences, Army Medical University

Shan Jiang

College of Basic medical Sciences, Army Medical University

Dan Zhong

College of Basic Medical Sciences,Army Medical University

\section{Zhizhen Xu}

College of Basic Medical Sciences, Army Medical University

\section{Quanfang Wei}

College of Basic Medical Sciences, Army Medical University

\section{Chunmong Shi}

Rocket Force Medicine, College of Preventive Medicine, Army Medical University

\section{Research}

Keywords: Liver X receptor, Hepatocellular carcinoma, HULC, miR-134-5p, FOXM1, Cell growth

Posted Date: February 4th, 2020

DOl: https://doi.org/10.21203/rs.2.22627/v1

License: (1) (i) This work is licensed under a Creative Commons Attribution 4.0 International License.

Read Full License 


\section{Abstract}

Background Highly upregulated in liver cancer (HULC), the specifically overexpressed long non-coding RNA (IncRNA) in human hepatocellular carcinoma (HCC), can promote the growth and metastasis of HCC cells. Therefore, it will be benefit to HCC treatment by effectively downregulating HULC. Liver X receptor (LXR), a member of nuclear receptor superfamily, exerts anti-tumor effects on various human malignancies including HCC. However, it is unclear whether the anti-HCC function of LXR is involved in the regulation of HULC.

Methods Quantitative real-time PCR and Western blot were used to separately examine RNA and protein levels in HCC cells. Cell counting kit-8 assay was used to detect the growth of HCC cells in vitro . Dualluciferase reporter assays were performed to analyze the regulation of forkhead box M1 (FOXM1) by miR134-5p and the regulation of miR-134-5p by HULC. Xenograft models were engaged to evaluate the growth of HCC cells in vivo .

Results In this study, we found that activation of LXR could inhibit the growth of HCC cells by downregulating HULC. Mechanistically, LXR decreased HULC via suppressing its gene promoter activity. Moreover, HULC and FOXM1 were highly expressed while miR-134-5p was lowly expressed in HCC tissues, and the level of HULC was positively correlated with that of FOXM1 while negatively correlated with that of miR-134-5p. Additionally, miR-134-5p downregulated FOXM1 by targeting 3'-untranslated region (UTR) of its MRNA, and HULC upregulated FOXM1 and its downstream target molecule cyclin D1 through sequestrating miR-134-5p. Furthermore, activation of LXR increased miR-134-5p while decreased FOXM1 by reducing HULC in HCC cells. The in vivo experiments showed that activation of LXR repressed the growth of HCC xenografts, and decreased HULC, FOXM1 and cyclin D1 while increased miR-134-5p in the xenografts.

Conclusions Our results for the first time reveal that LXR can inhibit the growth of HCC cells by regulating HULC/miR-134-5p/FOXM1 axis. The novel pathway LXR/HULC/miR-134-5p/FOXM1 may serve as a promising target in HCC treatment.

\section{Background}

Long non-coding RNAs (IncRNAs) are a class of non-protein-coding RNAs with longer than 200 nucleotides in length. Accumulating evidences have demonstrated that IncRNAs play crucial roles in multiple biological processes and participate in numerous human diseases [1-3]. Highly upregulated in liver cancer (HULC) is first identified as the specifically overexpressed IncRNA in human hepatocellular carcinoma (HCC) tissues [4]. It has been reported that HULC can promote HCC cell survival, proliferation, migration and invasion [5-7]. Moreover, HULC can trigger autophagy to attenuate the chemosensitivity of HCC cells [8]. Therefore, it will be benefit to HCC treatment by effectively downregulating HULC.

Liver $X$ receptor (LXR) belongs to ligand-activated nuclear receptor superfamily. Previous reports have shown that LXR plays important roles in regulating the metabolisms of glucose, lipid and cholesterol by 
binding to LXR response elements (LXREs) of its targeting genes $[9,10]$. Interestingly, the recent studies have revealed that LXR exerts anti-tumor effects on various cancers such as HCC, breast cancer, prostate cancer, ovarian cancer, and colorectal cancer [11-16], suggesting that LXR is a potential target in cancer treatment. However, it is not well known about the mechanisms by which LXR plays its anti-tumor function, especially, it is unclear whether the anti-HCC effect of LXR is involved in the regulation of HULC.

In the present study, we for the first time demonstrated that LXR could reduce the expression of HULC, leading to the upregulation of miR-134-5p and the subsequent downregulation of forkhead box M1 (FOXM1), which contributed to the growth inhibition of HCC cells in vitro and in vivo. These findings reveal that LXR can suppress HCC cell growth by modulating HULC/miR-134-5p/FOXM1 axis, which is a novel anti-HCC mechanism of LXR, suggesting that the pathway LXR/HULC/miR-134-5p/FOXM1 may be a promising target for $\mathrm{HCC}$ treatment.

\section{Methods}

\section{Collection of HCC tissues and cell culture}

A total of $30 \mathrm{HCC}$ tissues and the corresponding adjacent noncancerous tissues were collected from patients who had undergone surgery to remove tumors in the Department of Hepatobiliary Surgery, Xinqiao Hospital, Army Medical University (Third Military Medical University), Chongqing, China. Fresh tissue samples were collected and snap frozen in liquid nitrogen until use. The study was approved by the Ethics Committee of Army Medical University (Third Military Medical University).

Human HCC cell lines HepG2 and Hep3B were purchased from China Center for Type Culture Collection (Shanghai, China), and cultured in Dulbecco's modified Eagle's medium (Hyclone) with $10 \%$ fetal bovine serum (Hyclone), streptomycin $(100 \mathrm{mg} / \mathrm{mL})$ and penicillin $(100 \mathrm{U} / \mathrm{mL})$ at $37{ }^{\circ} \mathrm{C}$ in a $5 \% \mathrm{CO}_{2}$ humid incubator. To activate LXR in HCC cells, the LXR agonist GW3965 or T0901317 (Sigma) was used.

\section{Quantitative real-time PCR (qPCR)}

For examination of mRNAs and IncRNA HULC, total RNAs were extracted from HCC cells, HCC tissues or xenografts with TRIzol reagent (Invitrogen), and then the first-strand cDNA was synthesized using M-MLV reverse transcriptase (Invitrogen). qPCR was performed with SYBR green qPCR master mix (Promega) according to the manufacturer's protocol, taking $\beta$-actin as an internal control. MicroRNAs (miRNAs or miRs $\llbracket$ were extracted with miRNA isolation kit (OMEGA), and the expression of miR-134-5p was detected using miRNA quantitative reverse transcriptase PCR detection kit (GeneCopoeia) according to the manufacturer's instructions, which was normalized to that of U6 small nuclear RNA (U6 snRNA). The corresponding primer sequences were listed as follows: 


\begin{tabular}{|c|c|c|}
\hline Targets & Forward primers & Reverse primers \\
\hline HULC & 5'-ATCTGCAAGCCAGGAAGAGTC-3' & 5'-CTTGCTTGATGCTTTGGTCTGT-3' \\
\hline miR-134 & $\begin{array}{l}\text { 5'-TGTGACTGGTTGACCAGAGGGG- } \\
3^{\prime}\end{array}$ & $\begin{array}{l}\text { Universal Adaptor PCR Primer (supplied in the } \\
\text { kit) }\end{array}$ \\
\hline FOXM1 & $\begin{array}{l}\text { 5'-AGTAGTGGGCCCAACAAATTCAT- } \\
\text { 3' }\end{array}$ & 5'-CTTTTGGCATCATAGCTGGTTTG-3' \\
\hline CyclinD1 & 5'-CGCCССАССССТCCAG-3' & 5'-CCGCCCAGACCCTCAGACT-3' \\
\hline$\beta$-actin & $\begin{array}{l}\text { 5'-GTGAAGGTGACAGCAGTCGGTT- } \\
3^{\prime}\end{array}$ & 5'-GAAGTGGGGTGGCTTTTAGGA-3' \\
\hline $\begin{array}{l}\text { U6 } \\
\text { snRNA }\end{array}$ & $\begin{array}{l}\text { 5'-CGCTTCGGCAGCACATATACTAA- } \\
3^{\prime}\end{array}$ & 5'-TATGGAACGCTTCACGAATTTGC-3' \\
\hline
\end{tabular}

\section{Cell counting kit-8 (CCK-8) assay}

HCC cells were seeded into 96-well plates for $16 \mathrm{~h}$, and then transfected with HULC-expressing plasmid for $12 \mathrm{~h}$ or small interfering RNA (siRNA) for $24 \mathrm{~h}$ using Lipofectamine 2000 (Invitrogen) according to the manufacturer's protocol. Subsequently, the cells were treated with LXR agonist for different times, followed by the addition of $10 \mu \mathrm{L}$ CCK-8 reagent (Dojindo Laboratories) in each well according to the manufacturer's instructions. After incubation at $37^{\circ} \mathrm{C}$ for $4 \mathrm{~h}$, the optical density (OD) values at $450 \mathrm{~nm}$ were measured with a microplate reader, and the cell growth curves were drawn according to the $\mathrm{OD}_{450}$ values.

\section{Construction of plasmids}

The DNA fragment encoding human HULC was chemically synthesized by Sangon Biotech Corporation (Shanghai, China) and inserted into the expression vector pcDNA3.1 (Invitrogen), and the resulting plasmid was named pcDNA-HULC. The sequences of HULC promoter region containing the predicted wild type LXRE DR4 (DR4-WT) or mutant DR4 (DR4-Mut) were synthesized by Sangon Biotech Corporation and separately cloned into pGL3-Basic vector (Promega), and the resulting plasmids were named pGL3DR4-WT and pGL3-DR4-Mut respectively. The DNA fragments encoding the 3'-UTR of FOXM1 mRNA containing the predicted miR-134-5p wild type or mutant binding site were synthesized by Sangon Biotech Corporation, and then separately inserted into pmirGLO dual-luciferase miRNA target expression vector (Promega), and the resulting plasmids were named pmir-FOXMUTR-WT and pmir-FOXMUTR-Mut respectively. The HULC-encoding DNA fragments containing the predicted miR-134-5p wild type or mutant binding site were synthesized by GenePharma (Shanghai, China) and separately cloned into psiCHECK dual-luciferase reporter vector (Promega), and the resulting plasmids were named psi-HULC-miR-WT and psi-HULC-miR-Mut respectively. 


\section{Dual-luciferase reporter assays}

HCC cells were transfected with the luciferase reporter plasmids using Lipofectamine 2000 according to the manufacturer's protocol in the presence of different treatments. Then the cells were harvested and lysed, and the luciferase activities were determined with dual-luciferase reporter assay kit (Promega) according to the manufacturer's instructions. The firefly luciferase activity was normalized to that of renilla luciferase activity, and the result was shown as relative luciferase activity.

\section{Western blot}

Whole proteins were extracted from HCC cells or xenografts with RIPA lysis buffer (Beyotime Biotechnology) and then separated by $12 \%$ SDS-PAGE gels, followed by transfer to Immobilon-P PVDF membranes (Millipore). Subsequently, the membranes were blocked with $5 \%$ fat-free dry milk in Trisbuffered saline containing $0.1 \%$ Tween-20, and then separately incubated overnight at $4{ }^{\circ} \mathrm{C}$ with primary antibodies against FOXM1(Abcam), cyclin D1 (Abcam) or control $\beta$-actin (Abcam). After washing, the membranes were incubated with horseradish peroxidase-conjugated secondary antibody (CST) for $1 \mathrm{~h}$. Next, the membranes were washed, and the enhanced chemiluminescence detection reagents (Pierce) were used to visualize the signals.

\section{Animal experiments}

Eight-week-old male nude mice were purchased from Beijing Huafukang Bioscience (Beijing, China), and cared for under the guidelines of the Animal Care and Use Committee of Army Medical University (Third Military Medical University, Chongqing, China). A total of $5 \times 10^{6} \mathrm{Hep} 3 \mathrm{~B}$ cells were subcutaneously injected into the right axilla of each nude mouse. When palpable tumors formed, the mice were randomly divided into control and test groups ( $n=5$ per group). The control group was received a daily intraperitoneal injection with vehicle control soyabean oil for 12 days, while the test group was received the same treatment with LXR agonist GW3965 $(30 \mathrm{mg} / \mathrm{kg})$ [12]. Subsequently, the mice were sacrificed and the xenograft tumors were harvested and photographed, and the tumor volumes were measured using the formula: volume $=$ width $^{2} \times$ length $\times 1 / 2$. Meanwhile, the xenograft tumors were used for immunohistochemical staining or analysis of the expression of HULC, miR-134-5p, FOXM1 and its downstream target molecule cyclin D1.

\section{Immunohistochemical staining}


The harvested xenograft tumors were fixed with $4 \%$ polyoxymethylene, and then paraffin-embedded and sectioned. The sections were incubated overnight at $4{ }^{\circ} \mathrm{C}$ with the primary antibody against Ki67 (Santa Cruz). After warming and cleaning, the sections were incubated with peroxidase-conjugated secondary antibody (CST). Finally, diaminobenzidine was used to visualize the Ki67 signal, and the sections were observed under photomicroscope.

\section{Statistical analysis}

Statistical analysis was performed using GraphPad Prism 5. All data were presented as means \pm standard deviation (SD) unless otherwise stated. The differences were determined by using the Student $t$ test. $P<0.05$ was considered statistically significant.

\section{Results}

\section{LXR inhibits the growth of HCC cells by downregulating HULC}

As shown in Fig. 1a and b, activation of LXR dramatically decreased HULC. Moreover, activation of LXR suppressed the growth of HCC cells, which was markedly attenuated by ectopic expression of HULC (Fig. 1c, d). In addition, silence of HULC remarkably enhanced the LXR-mediated growth inhibition of HCC cells (Fig. 1e, f). Taken together, these results indicate that LXR can repress the growth of HCC cells through decreasing HULC.

\section{LXR reduces HULC by suppressing its gene promoter activity}

As a transcription factor, LXR usually regulates gene transcription by influencing the promoter activity of target gene. To inquiry the mechanism by which LXR downregulated HULC, the potential LXRE in HULC gene promoter region was predicted with online bioinformatics analysis (NUBIScan, www.nubiscan. unibas.ch/). As shown in Fig. 2a, a putative LXRE DR4 (-689 to -676) was found in HULC gene promoter region. Subsequently, the HULC gene promoter region $(-1010$ to +157$)$ containing DR4-WT(-689 to -676$)$ or DR4-Mut (Fig. 2a) was separately inserted into pGL3-Basic vector, and the resulting plasmids were named pGL3-DR4-WT and pGL3-DR4-Mut respectively. Next, the dual-luciferase reporter assays using the recombinant plasmids showed that activation of LXR significantly decreased the luciferase activity of pGL3-DR4-WT (but not pGL3-DR4-Mut) (Fig. 2b, c). These data reveal that LXR downregulates HULC via reducing its gene promoter activity, and the LXRE DR4 plays a crucial role in this process. 
The level of HULC is positively correlated with that of FOXM1 while negatively correlated with that of miR134-5p in HCC tissues

The above studies have demonstrated that LXR can suppress HCC cell growth by downregulating HULC. However, the action mechanism of HULC in HCC cells is not well known. Bioinformatics analysis by the online software Microlnspector showed that HULC may sponge miR-134-5p (Fig. 3a) (a microRNA that plays anti-tumor effects in various cancers including $\operatorname{HCC}[17,18])$. Moreover, the analyses with prediction algorithms (PicTar, TargetScan and miRanda) revealed that miR-134-5p may target 3'-UTR of FOXM1 mRNA (Fig. 3b). Previous reports have shown that FOXM1 plays promoting roles in multiple malignancies including HCC [19-21]. To preliminarily explore the relationship between HULC and FOXM1 (or miR-134$5 p)$, the levels of the three molecules were examined in HCC tissues and the corresponding adjacent noncancerous tissues. As shown in Fig. 3c-e, HULC and FOXM1 were highly expressed while miR-134-5p was lowly expressed in HCC tissues compared to the corresponding adjacent noncancerous tissues. There was a positive correlation between the expression of HULC and FOXM1 (Fig. 3f), while there was a negative correlation between the levels of HULC and miR-134-5p (Fig. $3 \mathrm{~g}$ ). Collectively, these data suggest that HULC may sequestrate miR-134-5p, leading to the elevation of FOXM1.

\section{miR-134-5p downregulates FOXM1 by targeting 3'-UTR of its mRNA in HCC cells}

As shown in Fig. 4a, treatment with miR-134-5p mimic obviously decreased the protein level of FOXM1 in HCC cells, which was markedly attenuated by miR-134-5p inhibitor. To investigate the mechanism by which miR-134-5p reduced FOXM1, the DNA fragments encoding 3'-UTR of FOXM1 mRNA containing the predicted miR-134-5p wild type or mutant binding site (Fig. 4b) were separately cloned into pmirGLO dualluciferase miRNA target expression vector, and the resulting plasmids were named pmir-FOXMUTR-WT and pmir-FOXMUTR-Mut respectively. Subsequently, the dual-luciferase reporter assays were performed using the recombinant plasmids. As shown in Fig. $4 c$ and d, miR-134-5p mimic dramatically repressed the luciferase activity of pmir-FOXMUTR-WT (but not pmir-FOXMUTR-Mut), which was remarkably alleviated by miR-134-5p inhibitor. These results prove that miR-134-5p downregulates FOXM1 by targeting the 3'UTR of its mRNA in HCC cells.

\section{HULC upregulates FOXM1 by sequestrating miR-134-5p in HCC cells}

As shown in Fig. 5a and b, overexpression of HULC in HCC cells dramatically increased the expression of FOXM1 and its downstream target gene cyclin D1 (Cyclin D1 is considered a functional indicator of FOXM1), while silence of HULC significantly decreased the expression of FOXM1 and cyclin D1. These results verify that the HULC-upregulated FOXM1 is functional in HCC cells. Next, we investigated whether miR-134-5p was involved in the HULC-mediated upregulation of FOXM1. As shown in Fig. 5c and d, ectopic expression of HULC in HCC cells reduced miR-134-5p while elevated FOXM1. Conversely, 
knockdown of HULC with siRNA increased miR-134-5p while decreased FOXM1 (Fig. 5c, d). Additionally, miR-134-5p mimic could decrease the expression of FOXM1, and the HULC-induced elevation of FOXM1 was markedly attenuated by miR-134-5p mimic (Fig. 5e). These data indicate that HULC can promote FOXM1 expression by suppressing miR-134-5p. Furthermore, the HULC-encoding DNA fragments containing the predicted miR-134-5p wild type binding site (5'-GTCGTCACGAGAACCAGACCAT-3') or mutant binding site (5'-GTCGTCACGAGGGTTCAACCAT-3', the mutated bases were underlined) were separately cloned into psiCHECK dual-luciferase reporter vector, and the resulting plasmids were named psi-HULC-miR-WT and psi-HULC-miR-Mut respectively. Subsequently, the dual-luciferase reporter assays were performed using the recombinant plasmids. As shown in Fig. $5 f$ and g, treatment with miR-134-5p mimic significantly reduced the luciferase activity of psi-HULC-miR-WT (but not psi-HULC-miR-Mut), which was dramatically attenuated by miR-134-5p inhibitor. Taken together, these results indicate that HULC upregulates FOXM1 through sequestrating miR-134-5p.

\section{LXR upregulates miR-134-5p while downregulates FOXM1 by reducing HULC in HCC cells}

The above studies have clarified that LXR can decrease HULC, while HULC can increase FOXM1 by sequestrating miR-134-5p. Then the effect of LXR on HULC/miR-134-5p/FOXM1 axis was assayed. As shown in Fig. $6 a$ and $b$, activation of LXR in HCC cells significantly decreased HULC and FOXM1, while increased miR-134-5p. Moreover, overexpression of HULC markedly alleviated the LXR-mediated miR-134$5 p$ upregulation and FOXM1 downregulation (Fig. 6c, d). These data reveal that LXR elevates miR-134-5p while reduces FOXM1 via downregulting HULC in HCC cells.

\section{Activation of LXR suppresses the growth of HCC xenografts and regulates the HULC/miR-134-5p/FOXM1 axis in vivo}

As shown Fig. 7a and b, activation of LXR dramatically inhibited the growth of HCC xenografts in nude mice. Immunohistochemical staining showed that LXR activation obviously reduced the expression of Ki67 (a marker of cell proliferation) in HCC xenografts (Fig. 6c). Furthermore, activation of LXR markedly decreased HULC, FOXM1 and cyclin D1 while increased miR-134-5p in the xenografts (Fig. 7d, e). These results indicate that activation of LXR represses the growth of HCC xenografts through regulating HULC/miR-134-5p/FOXM1 axis in vivo.

\section{Discussion}

It has been reported that both the nuclear receptor LXR and IncRNA HULC are associated with HCC. In general, LXR exerts anti-HCC effects [22-24], while HULC plays promoting functions on HCC [25-27]. However, it is unknown whether there is a relationship between LXR and HULC. In this study, we for the 
first time revealed that LXR downregulated HULC by repressing its gene promoter activity, leading to the growth inhibition of HCC cells. Besides HCC, LXR and HULC are also associated with other cancers such as breast cancer, prostate cancer, ovarian cancer and colorectal cancer [11-16, 28-31]. So further research is needed to see whether the LXR-mediated downregulation of HULC is also existence and functional in other cancers. Additionally, to our knowledge, this is the first evidence to show that LXR plays its roles by modulating IncRNA expression. Therefore, more studies are required to explore whether LXR can regulate other IncRNAs besides HULC.

Previous researches have demonstrated that miR-134-5p acts as a tumor suppressor. It can inhibit cancer cell proliferation and invasion, and attenuate drug resistance by regulating a variety of tumor related targets and signal pathways [32]. For examples, miR-134-5p dramatically suppresses the metastasis and malignancy of HCC by targeting integrin $\beta 1$ and k-RAS $[33,34]$. So investigating the modulating mechanism of miR-134-5p will be helpful to develop novel anti-HCC strategy. In the present study, we found that LXR markedly upregulated miR-134-5p by downregulating HULC. Moreover, HULC could sequestrate miR-134-5p, which remarkably attenuated the LXR-mediated growth inhibition of HCC cells. Due to the complicated action mechanisms of LXR and HULC, it is necessary to explore whether LXR can directly upregulate miR-134-5p and whether HULC can repress miR-134-5p through other mechanism. In addition, previous reports have shown that HULC can sponge miR-372 and miR-200a, leading to the promotion of tumorigenesis and metastasis of $\operatorname{HCC}[35,36]$. Therefore, further studies are needed to inquiry whether LXR is also involved in the regulation of these HULC-sponged microRNAs besides miR134-5p.

FOXM1, a member of the forkhead family of transcription factors, is essential for cell growth, survival and cell cycle progression [37]. Clinical investigations have revealed that FOXM1 is associated with tumorigenesis, progression and prognosis of cancer, which enables FOXM1 as a tumor marker in several kinds of malignancies including HCC [38-40]. Knockdown of FOXM1 decreases HCC cell proliferation, induces cell cycle arrest and inhibits cell invasion [41]. Downregulation of FOXM1 by p53 enhances chemosensitivity of HCC cells to oxaliplatin [42]. In this study, we showed that LXR dwonregulated FOXM1 while upregulated miR-134-5p through reducing HULC in HCC cells. Furthermore, miR-134-5p suppressed FOXM1 by targeting the 3'-UTR of its MRNA, while HULC elevated FOXM1 via sequestrating miR-134-5p. The four molecules formed the pathway LXR/HULC/miR-134-5p/FOXM1, which is a novel anti-HCC mechanism of LXR. Additionally, our previous study has verified that LXR represses FOXM1 in HCC cells by binding to FOXM1 gene promoter region [12], together with the data in the present study, indicating that LXR can regulate FOXM1 in direct and indirect ways. More studies are warranted regarding the significance of the different modulation mechanisms by which LXR regulates FOXM1 in HCC cells.

\section{Conclusions}

Collectively, we demonstrate that LXR can repress HCC cell growth through regulating HULC/miR-1345p/FOXM1 axis, which is a novel anti-HCC mechanism of LXR. Modulation of the pathway LXR/HULC/miR-134-5p/FOXM1 may represent a potential strategy for the treatment of HCC. 


\section{Abbreviations}

CCK8

Cell counting kit-8; FOXM1:Forkhead box M1; HCC:Human hepatocellular carcinoma; HULC:Highly upregulated in liver cancer; IncRNA:Long non-coding RNA; LXR:Liver X receptor; LXRE:LXR response element; miRNA (miR):MicroRNA; OD:Optical density; qPCR:Quantitative real-time polymerase chain reaction; siRNA:Small interfering RNA; snRNA:Small nuclear RNA; UTR:Untranslated region.

\section{Declarations}

\section{Ethics approval and consent to participate}

Usage of HCC tissues and the corresponding adjacent noncancerous tissues was approved by the Ethics Committee of Army Medical University (Third Military Medical University). All the mouse experiments were approved by the Animal Care and Use Committee of Army Medical University (Third Military Medical University).

\section{Consent for publication}

Not Applicable.

\section{Availability of data and materials}

All data generated in this study are included in the manuscript.

\section{Competing interests}

The authors declare that they have no competing interests.

\section{Funding}

This work was supported by National Nature Science Foundation of China (81672377 and 81402035), Natural Science Foundation Project of Chongqing (cstc2017jcyjBX0079), and Talents Training Program of Army Medical University. 


\section{Authors' contributions}

$\mathrm{JH}, \mathrm{YZ}$ and $\mathrm{CS}$ designed the experiments, analyzed the data and wrote the manuscript. JH, YZ, TY, WH, SJ, DZ and ZX conducted the experiments. QW helped with analyzing the data. CS and $Y Z$ were major guarantors of the present work and had full access to all the data. YZ performed the manuscript submission. All authors read and approved the final manuscript.

\section{Acknowledgements}

Not applicable.

\section{References}

1.

Ponting CP, Oliver PL, Reik W. Evolution and functions of long noncoding RNAs. Cell. 2009;136(4):62941.

2.

Wapinski O, Chang HY. Long noncoding RNAs and human disease. Trends Cell Biol. 2011;21(6):354-61. 3.

Schmitt AM, Chang HY. Long Noncoding RNAs in Cancer Pathways. Cancer cell. 2016;29(4):452-63.

4.

Panzitt K, Tschernatsch MM, Guelly C, Moustafa T, Stradner M, Strohmaier HM, et al. Characterization of HULC, a novel gene with striking up-regulation in hepatocellular carcinoma, as noncoding RNA. Gastroenterology. 2007;132(1):330-42.

5 .

Cui M, Xiao Z, Wang Y, Zheng M, Song T, Cai X, et al. Long noncoding RNA HULC modulates abnormal lipid metabolism in hepatoma cells through an miR-9-mediated RXRA signaling pathway. Cancer Res. 2015;75(5):846-57.

6.

Yu X, Zheng H, Chan MT, Wu WK. HULC: an oncogenic long non-coding RNA in human cancer. J Cell Mol Med. 2017;21(2):410-7.

7.

Li C, Chen J, Zhang K, Feng B, Wang R, Chen L. Progress and Prospects of Long Noncoding RNAs (IncRNAs) in Hepatocellular Carcinoma. Cell Physiol Biochem. 2015;36(2):423-34.

8.

Xiong $\mathrm{H}, \mathrm{Ni}$ Z, He J, Jiang S, Li X, He J, et al. LncRNA HULC triggers autophagy via stabilizing Sirt1 and attenuates the chemosensitivity of HCC cells. Oncogene. 2017;36(25):3528-40.

9. 
Wang B, Tontonoz P. Liver X receptors in lipid signalling and membrane homeostasis. Nat Rev Endocrinol. 2018;14(8):452-63.

10.

Hiebl V, Ladurner A, Latkolik S, Dirsch VM. Natural products as modulators of the nuclear receptors and metabolic sensors LXR, FXR and RXR. Biotechnol Adv. 2018;36(6):1657-98.

11.

Long H, Guo X, Qiao S, Huang Q. Tumor LXR Expression is a Prognostic Marker for Patients with Hepatocellular Carcinoma. Pathol Oncol Res. 2018;24(2):339-44.

12.

Hu C, Liu D, Zhang Y, Lou G, Huang G, Chen B, et al. LXRalpha mediated downregulation of FOXM1 suppresses the proliferation of hepatocellular carcinoma cells. Oncogene. 2014;33(22):2888-97. 13.

Vedin LL, Lewandowski SA, Parini P, Gustafsson JA, Steffensen KR. The oxysterol receptor LXR inhibits proliferation of human breast cancer cells. Carcinogenesis. 2009;30(4):575-9.

14.

Fukuchi J, Kokontis JM, Hiipakka RA, Chuu CP, Liao S. Antiproliferative effect of liver X receptor agonists on LNCaP human prostate cancer cells. Cancer Res. 2004;64(21):7686-9.

15.

Scoles DR, Xu X, Wang H, Tran H, Taylor-Harding B, Li A, et al. Liver X receptor agonist inhibits proliferation of ovarian carcinoma cells stimulated by oxidized low density lipoprotein. Gynecol Oncol. 2010;116(1):109-16.

16.

Derangère $V$, Chevriaux $A$, Courtaut $F$, Bruchard $M$, Berger $H$, Chalmin $F$, et al. Liver $X$ receptor $\beta$ activation induces pyroptosis of human and murine colon cancer cells. Cell Death Differ. 2014;21(12):1914-24. 17.

Zha R, Guo W, Zhang Z, Qiu Z, Wang Q, Ding J, et al. Genome-wide screening identified that miR-134 acts as a metastasis suppressor by targeting integrin $\beta 1$ in hepatocellular carcinoma. PLoS One. 2014;9(2):e87665.

18.

Yin C, Wang PQ, Xu WP, Yang Y, Zhang Q, Ning BF, et al. Hepatocyte nuclear factor-4a reverses malignancy of hepatocellular carcinoma through regulating miR-134 in the DLK1-DIO3 region. Hepatology. 2013;58(6):1964-6.

19.

Chai N, Xie HH, Yin JP, Sa KD, Guo Y, Wang M, et al. FOXM1 promotes proliferation in human hepatocellular carcinoma cells by transcriptional activation of CCNB1. Biochem Biophys Res Commun. 2018;500(4):924-9.

20.

Shang R, Pu M, Li Y, Wang D. FOXM1 regulates glycolysis in hepatocellular carcinoma by transactivating glucose transporter 1 expression. Oncol Rep. 2017;37(4):2261-9.

21. 
Egawa M, Yoshida Y, Ogura S, Kurahashi T, Kizu T, Furuta K, et al. Increased expression of Forkhead box M1 transcription factor is associated with clinicopathological features and confers a poor prognosis in human hepatocellular carcinoma. Hepatol Res. 2017;47(11):1196-205.

22.

Xiong T, Li Z, Huang X, Lu K, Xie W, Zhou Z, Tu J. T0901317 inhibits the development of hepatocellular carcinoma by LXRa/Glut1 decreasing glycometabolism. Am J Physiol Gastrointest Liver Physiol. 2019;316(5):G598-607.

23.

Morén A, Bellomo C, Tsubakihara Y, Kardassis D, Mikulits W, Heldin CH, et al. LXRa limits TGF $\beta$-dependent hepatocellular carcinoma associated fibroblast differentiation. Oncogenesis. 2019;8(6):36. 24.

Xiong H, Zhang Y, Chen S, Ni Z, He J, Li X, et al. Induction of SOCS3 by liver X receptor suppresses the proliferation of hepatocellular carcinoma cells. Oncotarget. 2017;8(38):64083-94.

25.

Xin X, Wu M, Meng Q, Wang C, Lu Y, Yang Y, et al. Long noncoding RNA HULC accelerates liver cancer by inhibiting PTEN via autophagy cooperation to miR15a. Mol Cancer. 2018;17(1):94.

26.

Wang Y, Chen F, Zhao M, Yang Z, Li J, Zhang S, et al. The long noncoding RNA HULC promotes liver cancer by increasing the expression of the HMGA2 oncogene via sequestration of the microRNA-186. J Biol Chem. 2017;292(37):15395-407.

27.

Xiong H, Li B, He J, Zeng Y, Zhang Y, He F. IncRNA HULC promotes the growth of hepatocellular carcinoma cells via stabilizing COX-2 protein. Biochem Biophys Res Commun. 2017;490(3):693-9.

28.

Shi F, Xiao F, Ding P, Qin H, Huang R. Long Noncoding RNA Highly Up-regulated in Liver Cancer Predicts Unfavorable Outcome and Regulates Metastasis by MMPs in Triple-negative Breast Cancer. Arch Med Res. 2016;47(6):446-53.

29.

Zheng P, Li H, Xu P, Wang X, Shi Z, Han Q, et al. High IncRNA HULC expression is associated with poor prognosis and promotes tumor progression by regulating epithelial-mesenchymal transition in prostate cancer. Arch Med Sci. 2018;14(3):679-86.

30 .

Chen S, Wu DD, Sang XB, Wang LL, Zong ZH, Sun KX, et al. The IncRNA HULC functions as an oncogene by targeting ATG7 and ITGB1 in epithelial ovarian carcinoma. Cell Death Dis. 2017;8(10):e3118.

31.

Yang XJ, Huang CQ, Peng CW, Hou JX, Liu JY. Long noncoding RNA HULC promotes colorectal carcinoma progression through epigenetically repressing NKD2 expression. Gene. 2016;592(1):172-8.

32.

Pan JY, Zhang F, Sun CC, Li SJ, Li G, Gong FY, et al. miR-134: A Human Cancer Suppressor? Mol Ther Nucleic Acids. 2017;6:140-9. 
33.

Zha R, Guo W, Zhang Z, Qiu Z, Wang Q, Ding J, et al. Genome-wide screening identified that miR-134 acts as a metastasis suppressor by targeting integrin $\beta 1$ in hepatocellular carcinoma. PLoS One. 2014;9(2):e87665.

34.

Yin C, Wang PQ, Xu WP, Yang Y, Zhang Q, Ning BF, et al. Hepatocyte nuclear factor-4a reverses malignancy of hepatocellular carcinoma through regulating miR-134 in the DLK1-DIO3 region. Hepatology. 2013;58(6):1964-76.

35.

Li SP, Xu HX, Yu Y, He JD, Wang Z, Xu YJ, et al. LncRNA HULC enhances epithelial-mesenchymal transition to promote tumorigenesis and metastasis of hepatocellular carcinoma via the miR-200a-3p/ZEB1 signaling pathway. Oncotarget. 2016;7(27):42431-46.

36 .

Wang J, Liu X, Wu H, Ni P, Gu Z, Qiao Y, et al. CREB up-regulates long non-coding RNA, HULC expression through interaction with microRNA-372 in liver cancer. Nucleic Acids Res. 2010;38(16):5366-83. 37.

Halasi M, Gartel AL. Targeting FOXM1 in cancer. Biochem Pharmacol. 2013;85(5):644-52. 38.

Yu CP, Yu S, Shi L, Wang S, Li ZX, Wang YH, et al. FoxM1 promotes epithelial-mesenchymal transition of hepatocellular carcinoma by targeting Snai1. Mol Med Rep. 2017;16(4):5181-8.

39.

Nandi D, Cheema PS, Jaiswal N, Nag A. FoxM1: Repurposing an oncogene as a biomarker. Semin Cancer Biol. 2018;52(Pt 1):74-84.

40.

Liao GB, Li XZ, Zeng S, Liu C, Yang SM, Yang L, et al. Regulation of the master regulator FOXM1 in cancer. Cell Commun Signal. 2018;16(1):57.

41.

Wu QF, Liu C, Tai MH, Liu D, Lei L, Wang RT, et al. Knockdown of FoxM1 by siRNA interference decreases cell proliferation, induces cell cycle arrest and inhibits cell invasion in MHCC-97H cells in vitro. Acta Pharmacol Sin. 2010;31(3):361-6.

42.

Qu K, Xu X, Liu C, Wu Q, Wei J, Meng F, et al. Negative regulation of transcription factor FoxM1 by p53 enhances oxaliplatin-induced senescence in hepatocellular carcinoma. Cancer Lett. 2013;331(1):105-14.

\section{Figures}


a

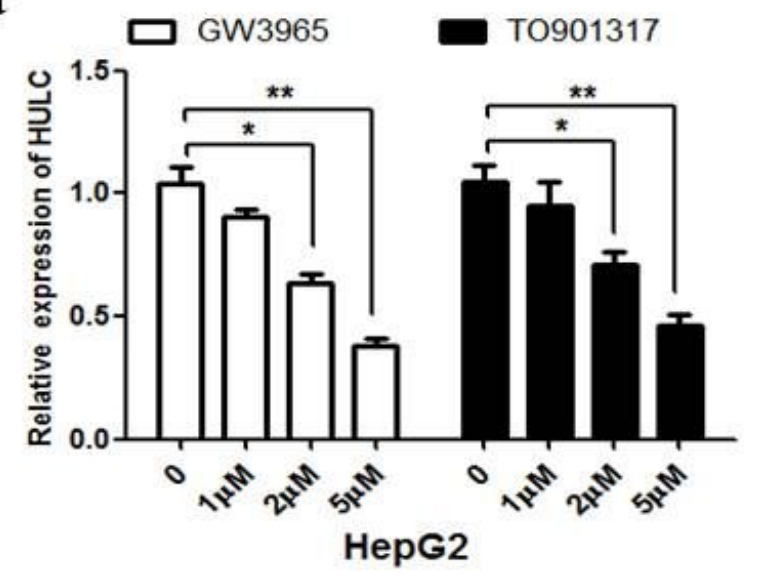

$\mathrm{c}$
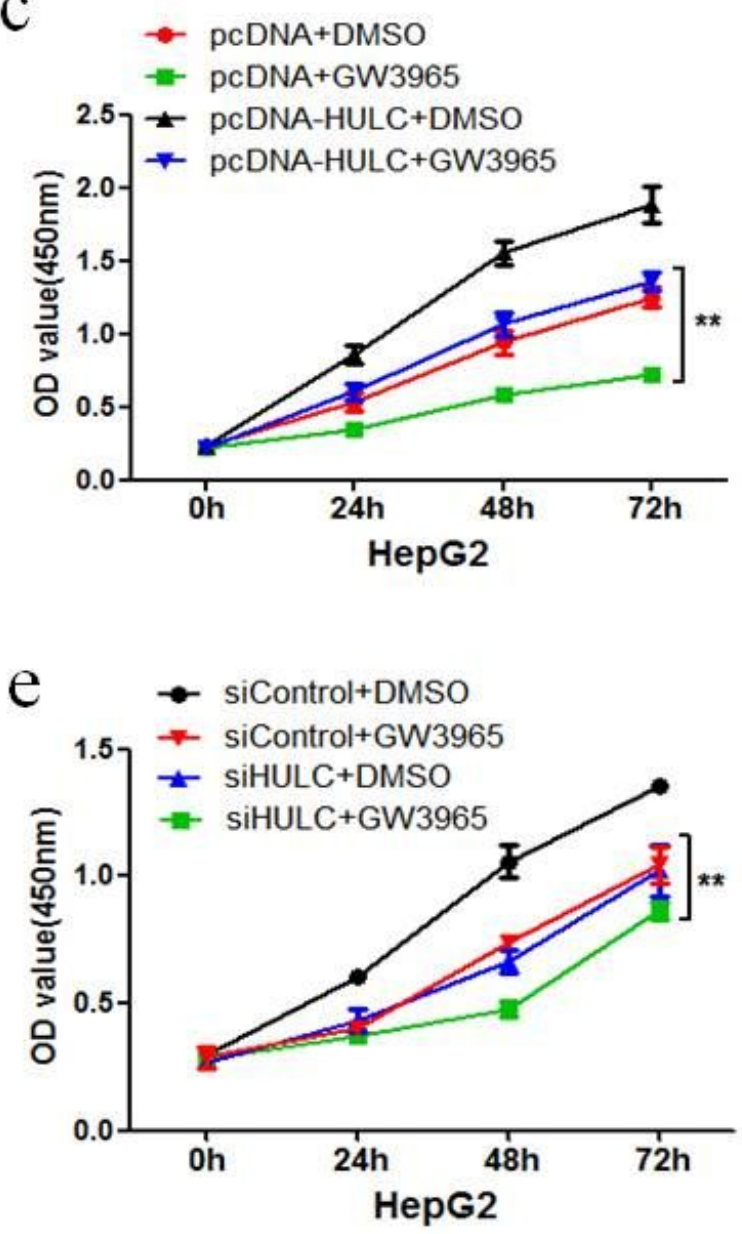

b

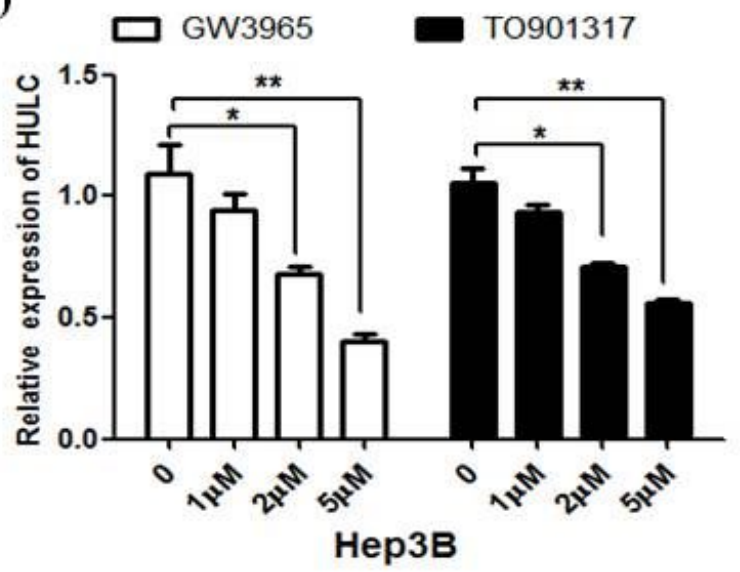

d
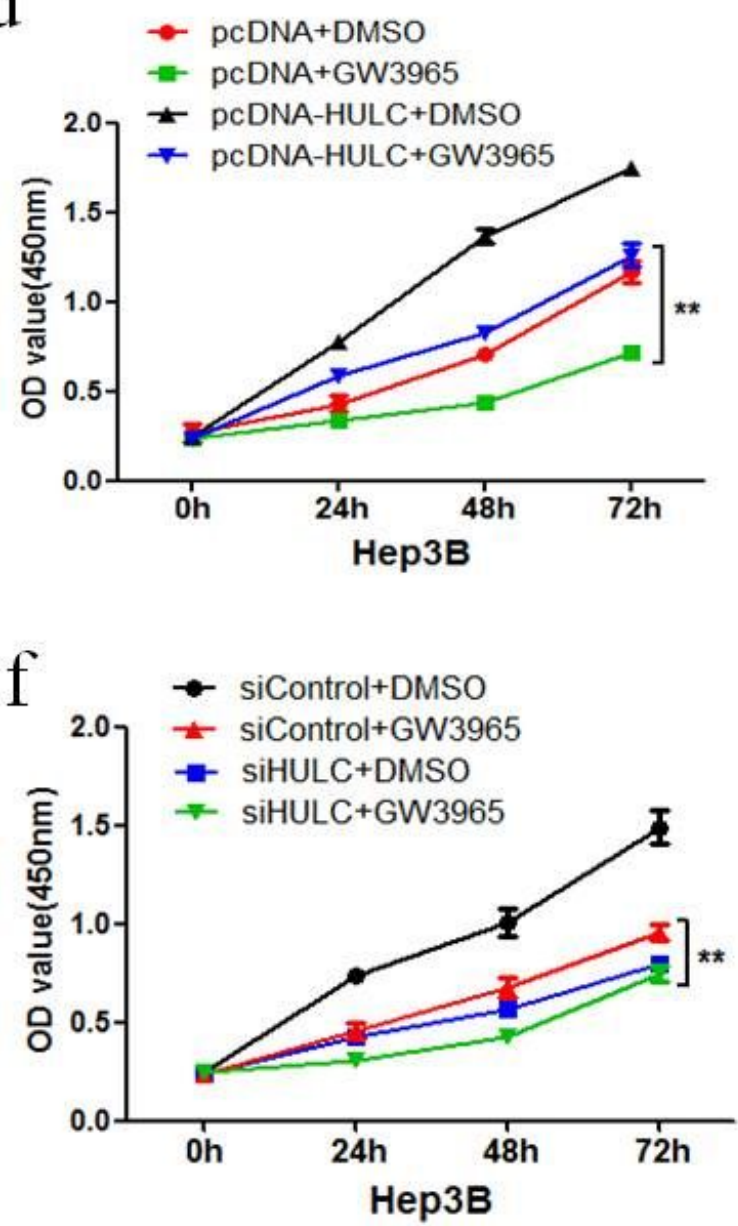

\section{Figure 1}

LXR inhibits the growth of HCC cells by downregulating HULC. a, b HepG2 (a) and Hep3B (b) cells were treated with vehicle control DMSO or the indicated concentrations of LXR agonist (GW3965 or T0901317) for $24 \mathrm{~h}$, and then the expression of HULC was determined by qPCR. c, d After transfected with control plasmid pcDNA3.1 (pcDNA) or HULC-expressing plasmid pcDNA-HULC for $12 \mathrm{~h}$, HepG2 (c)

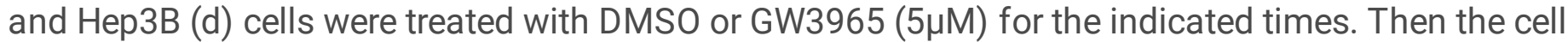


survival was detected using CCK-8 assay. e, f After transfected with HULC siRNA (siHULC) or negative control siRNA (siControl) for $24 \mathrm{~h}$, HepG2 (e) and Hep3B (f) cells were treated with DMSO or GW3965 $(5 \mu \mathrm{M})$ for the indicated times. Then the cell survival was examined with CCK-8 assay. Data are means \pm SD from three assays performed in triplicate. ${ }^{*} P<0.05,{ }^{*} \mathrm{P}<0.01$.
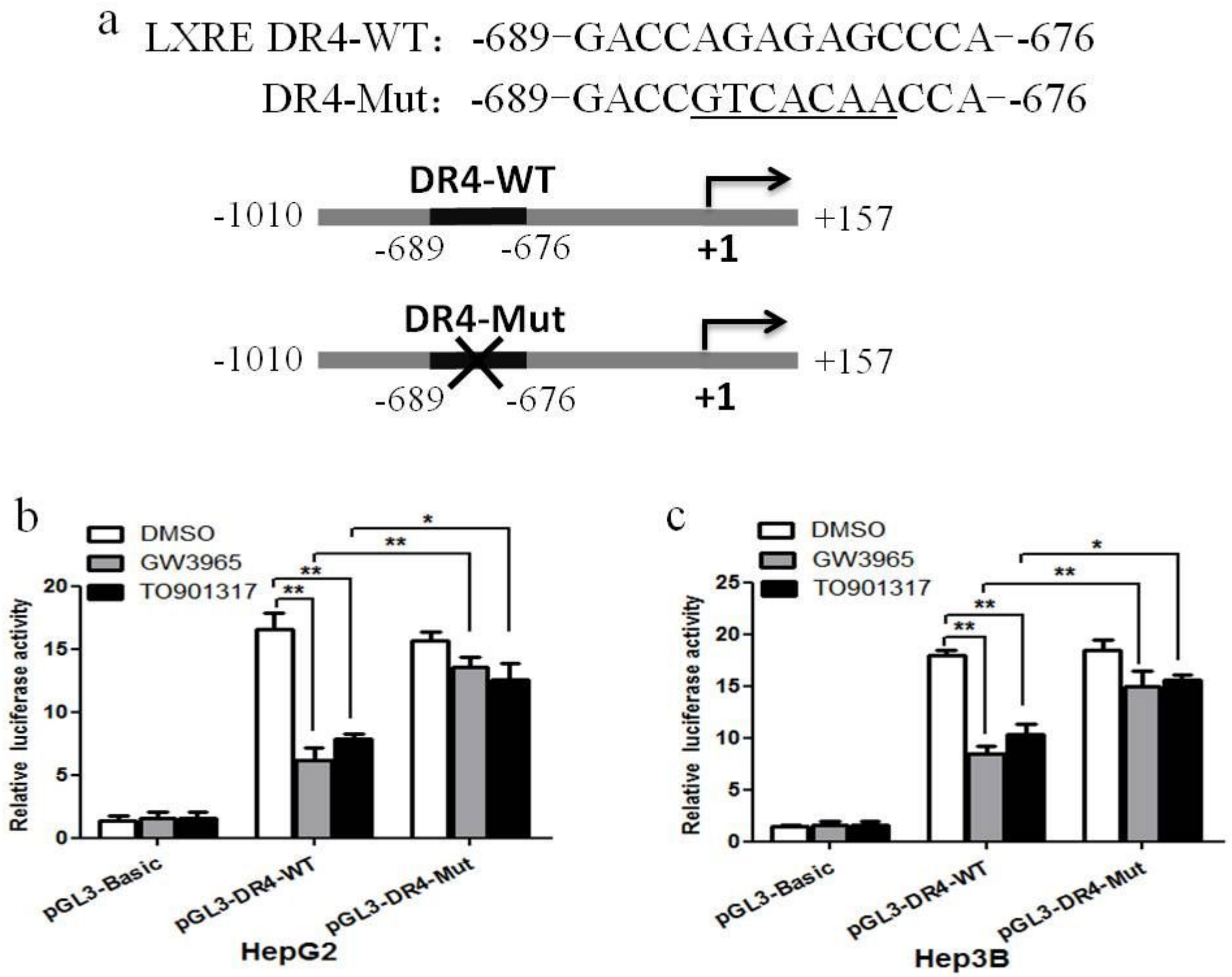

Figure 2

LXR downregulates HULC by suppressing its promoter activity. a Diagram of the potential LXRE DR4 (DR4-WT) in promoter region of HULC, and the mutated bases were underlined in the mutant DR4 (DR4Mut). b, c After cotransfected with luciferase reporter vector pGL3-DR4-WT (or pGL3-DR4-Mut or pGL3Basic) and pRL-TK vector for $12 \mathrm{~h}$, HepG2 (b) and Hep3B (c) cells were treated with DMSO (control) or 5 HM GW3965 (or T0901317) for $24 \mathrm{~h}$. Then the dual-luciferase reporter assays were performed. The firefly luciferase activity was normalized to that of renilla luciferase activity, and the result was shown as relative luciferase activity. Data are means \pm SD from three assays performed in triplicate. ${ }^{*} P<0.05, \star \star P<$ 0.01 . 
$\mathrm{a}$

HULC

5'-...GTCGTCACGAGAACCAGACCAT ...-3'

hsa-miR-134-5p 3'-GGGGAGACCAGUUGGUCAGUGU-5'

$\begin{array}{rc}\text { bOXM1 3'-UTR } & \text { 5'-...AUUAUGCAAAAGUAGCAGUCACA ...-3' } \\ & \\ \text { hsa-miR-134-5p } & \text { 3'-GGGGAGACCAGUUGGUCAGUGU-5' }\end{array}$

C
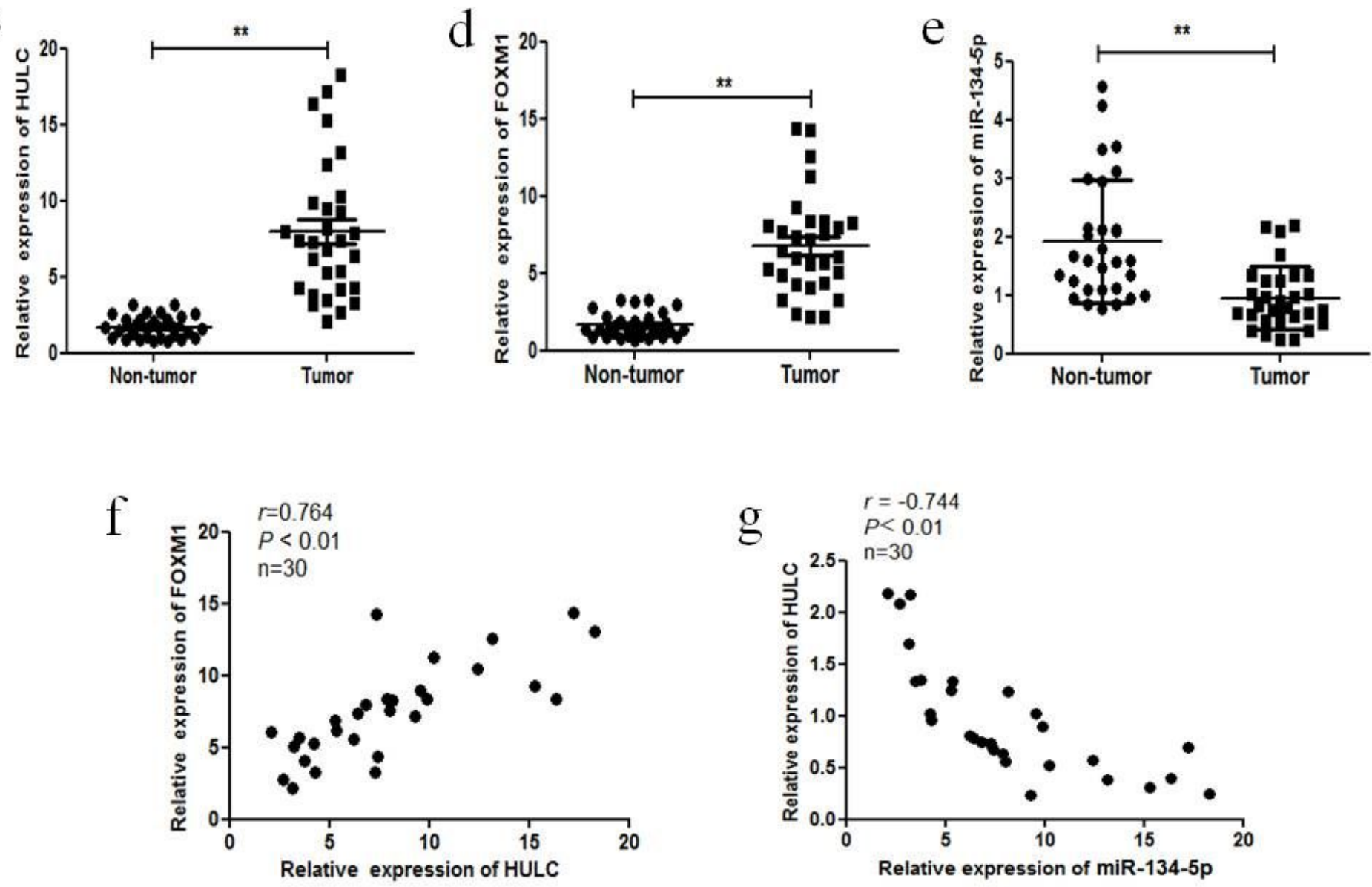

Figure 3

The level of HULC is positively correlated with that of FOXM1 while negatively correlated with that of miR134-5p in HCC tissues. a Diagrams of the predicted potential binding sites of miR-134-5p in HULC (a) and 3'-UTR of FOXM1 mRNA (b). c-e The expression of HULC (c), FOXM1 (d) and miR-134-5p (e) was examined by qPCR in $30 \mathrm{HCC}$ tissues and the corresponding adjacent noncancerous tissues. $\mathrm{f}, \mathrm{g}$ The correlation between the levels of HULC and FOXM1 mRNA (f) or miR-134-5p (g) in 30 HCC tissues was analyzed using Pearson's correlation coefficient. ${ }^{*} \mathrm{P}<0.01$. 
a

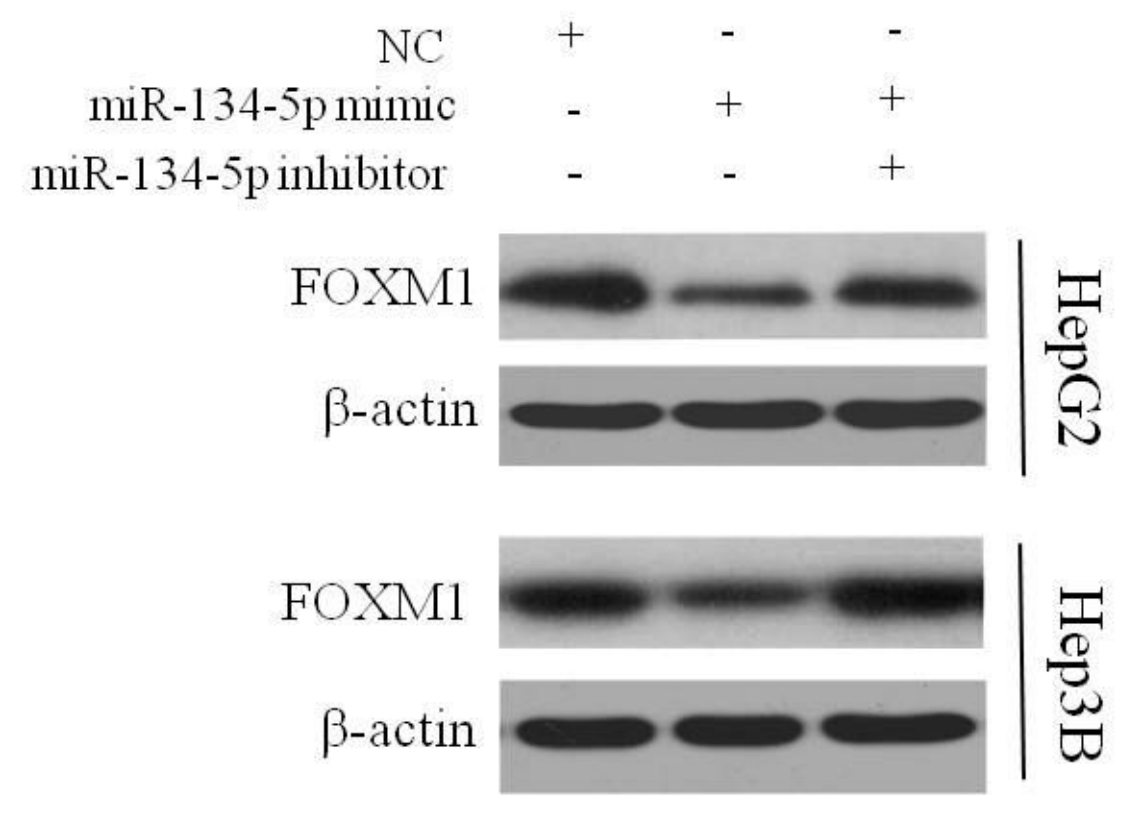

$\mathrm{b}$

FOXM1 3'-UTR WT 5'-..AUUAUGCAAAAGUAGCAGUCACA ...-3'

hsa-miR-134-5p 3'-GGGGAGACCAGUUGGUCAGUGU-5'

FOXM1 3'-UTR Mut 5'-...AUUAUGCAAAAGUAGCGUGAGUA...-3'
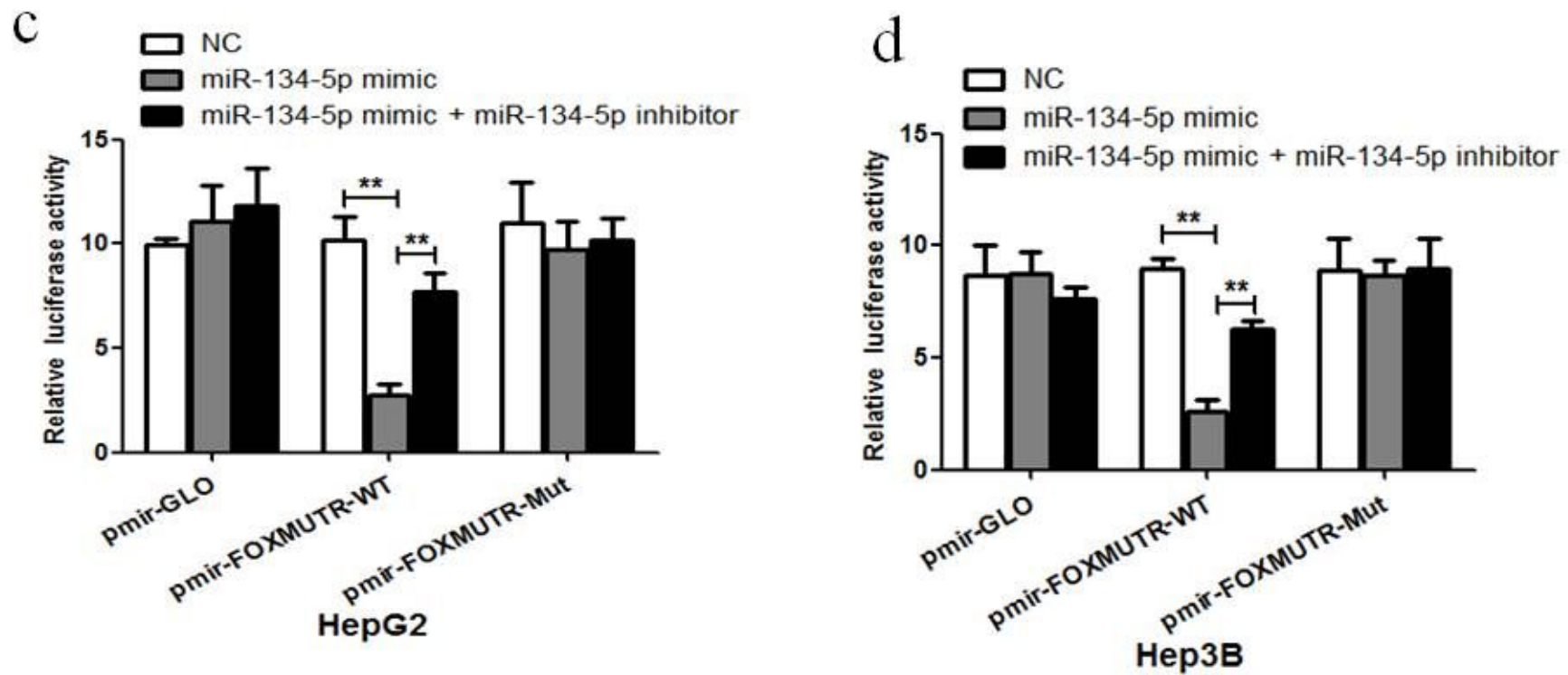

Figure 4

miR-134-5p downregulates FOXM1 by targeting 3'-UTR of its mRNA in HCC cells. a HepG2 and Hep3B cells were transfected with miR-134-5p mimic (or negative control, NC) or the combination of miR-134-5p mimic and inhibitor for $48 \mathrm{~h}$. Then the level of FOXM1 protein was measured with Western blot. $\mathrm{b}$ Diagrams of the potential wild type (WT) and mutant (Mut) binding sites of miR-134-5p in 3'-UTR of FOXM1 mRNA (the mutated bases were underlined). c, d HepG2 (c) and Hep3B (d) cells were transfected 
with the reporter plasmid pmir-FOXMUTR-WT (or pmir-FOXMUTR-Mut) in the presence of miR-134-5p mimic (or NC) or the combination of miR-134-5p mimic and inhibitor for $24 \mathrm{~h}$. Then the luciferase activities were detected with dual-luciferase reporter assays. The firefly luciferase activity was normalized to that of renilla luciferase activity, and the result was shown as relative luciferase activity. Data are means \pm SD from three assays performed in triplicate. $* * \mathrm{P}<0.01$.
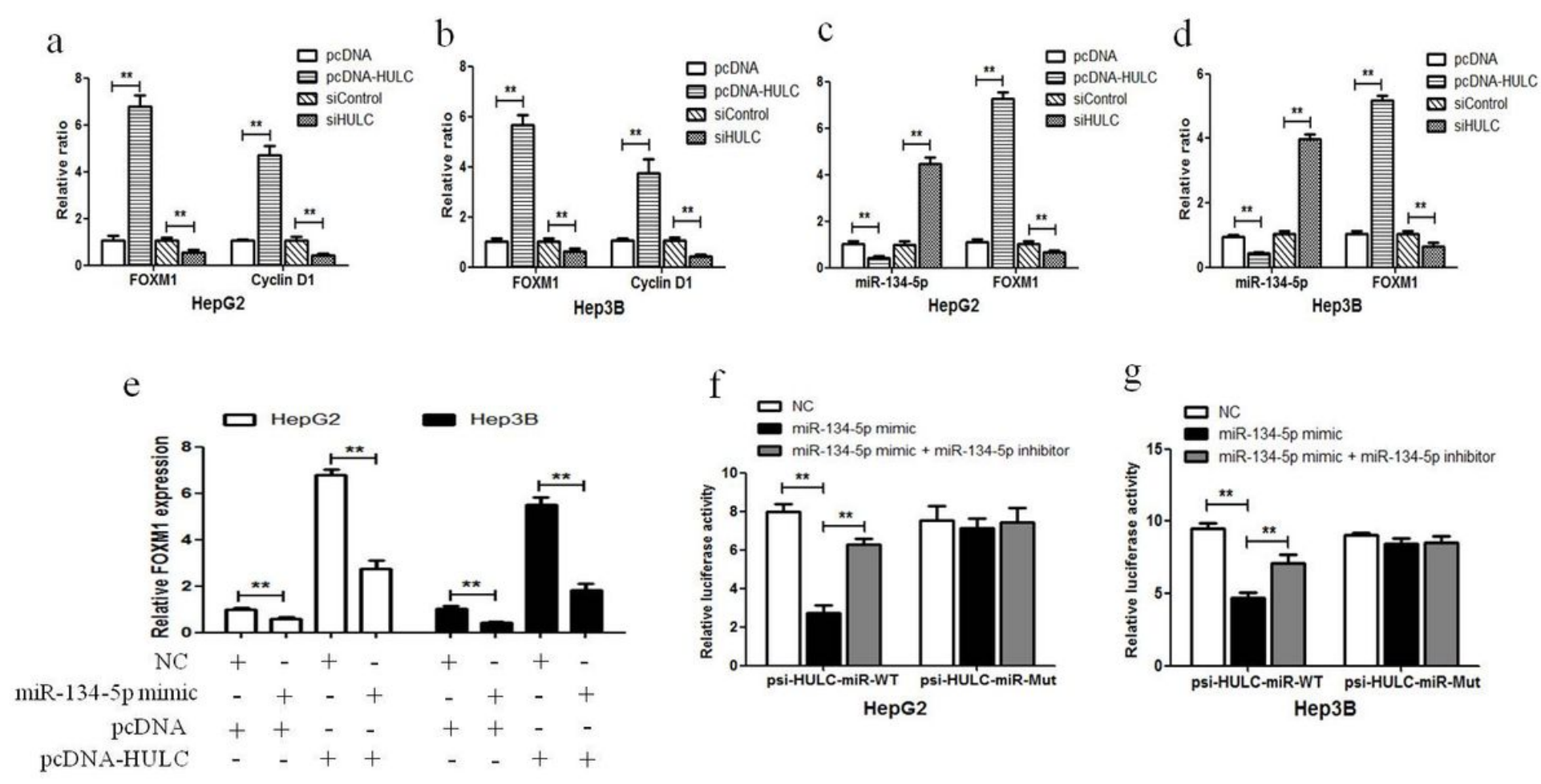

\section{Figure 5}

HULC upregulates FOXM1 by sequestrating miR-134-5p in HCC cells. a, b HepG2 (a) and Hep3B (b) cells were transfected with pcDNA3.1 (pcDNA) or HULC-expressing plasmid pcDNA-HULC, or HULC siRNA (siHULC) or negative control siRNA (siControl) for $24 \mathrm{~h}$. Then the mRNA levels of FOXM1 and cyclin D1 were tested by qPCR. c, d HepG2 (c) and Hep3B (d) cells were treated as in (a, b), and then the expression of miR-134-5p and FOXM1 was detected by qPCR. e HepG2 and Hep3B cells were cotransfected with miR-134-5p mimic ( or negative control, NC) and pcDNA-HULC (or pcDNA) for $24 \mathrm{~h}$, and then the expression of FOXM1 was examined with qPCR. $f, g$ HepG2 (f) and Hep3B (g) cells were transfected with the reporter plasmid psi-HULC-miR-WT (or psi-HULC-miR-Mut) in the presence of miR-134-5p mimic (or $\mathrm{NC}$ ) or the combination of miR-134-5p mimic and inhibitor for $24 \mathrm{~h}$. Then the luciferase activities were measured with dual-luciferase reporter assays. The firefly luciferase activity was normalized to that of renilla luciferase activity, and the result was shown as relative luciferase activity. Data are means $\pm S D$ from three assays performed in triplicate. ${ }^{*} \mathrm{P}<0.01$. 
a

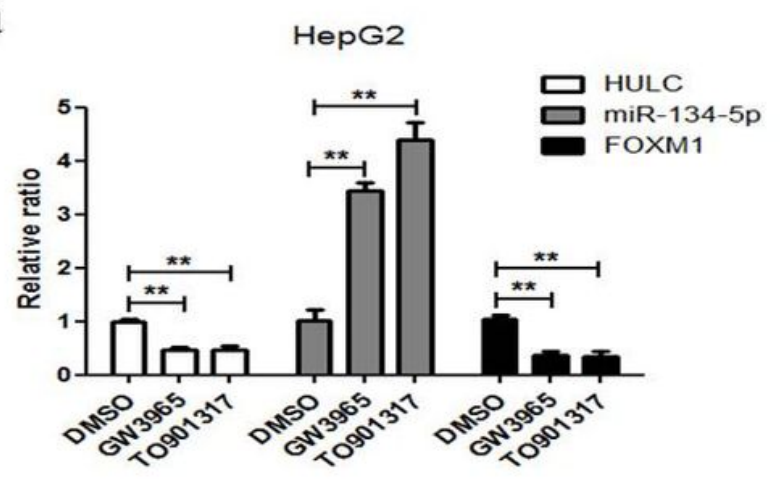

c
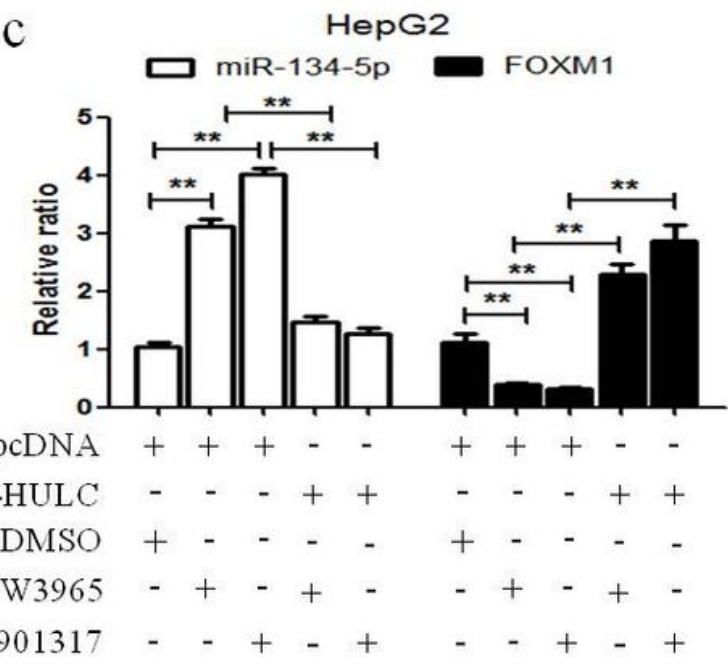

b

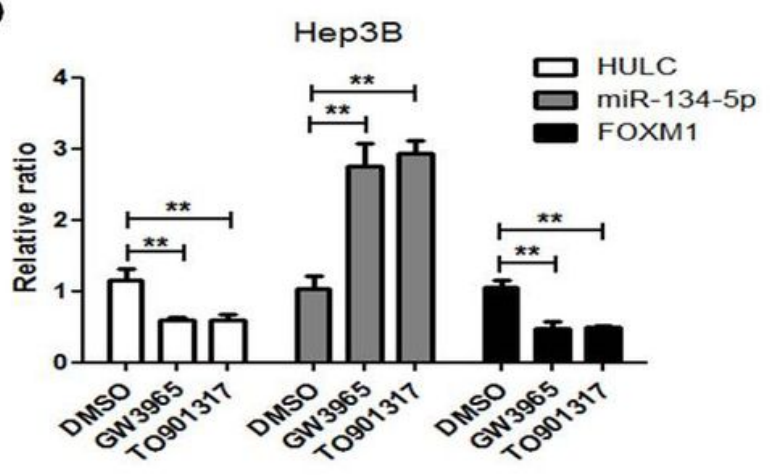

d

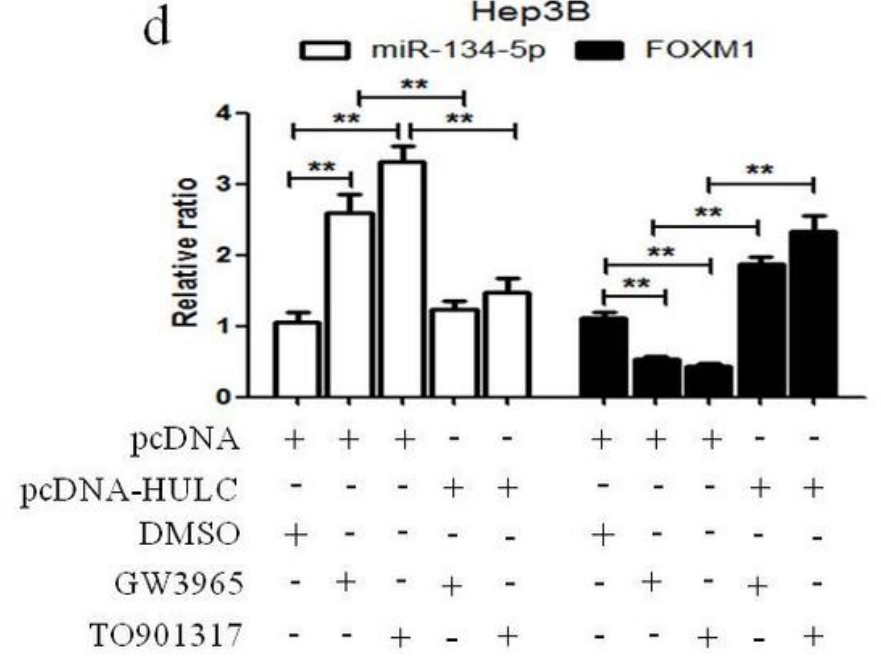

Figure 6

LXR upregulates miR-134-5p while downregulates FOXM1 by reducing HULC in HCC cells. a, b HepG2 (a)

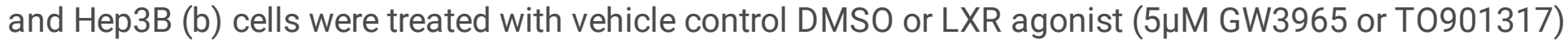
for $24 \mathrm{~h}$. Then the expression of HULC, miR-134-5p and FOXM1 was determined by qPCR. c, d After transfected with pcDNA3.1 (pcDNA) or HULC-expressing plasmid pcDNA-HULC for $12 \mathrm{~h}$, HepG2 (c) and Hep3B (d) cells were treated with DMSO or $5 \mu$ M GW3965 (or T0901317) for $24 \mathrm{~h}$. Then the expression of miR-134-5p and FOXM1 was determined by qPCR. ${ }^{*} \mathrm{P}<0.01$. 
a

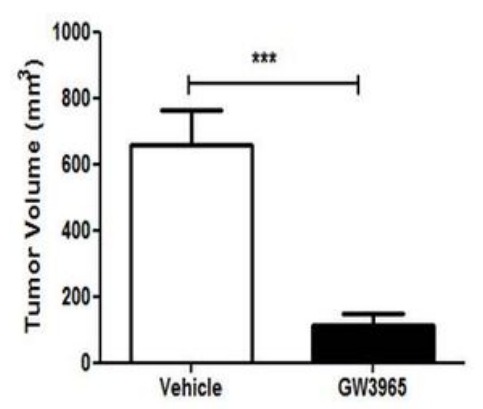

$\mathrm{b}$

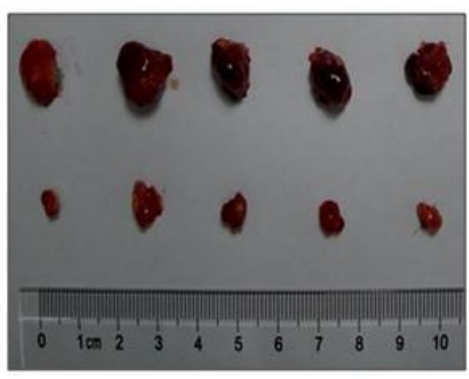

c

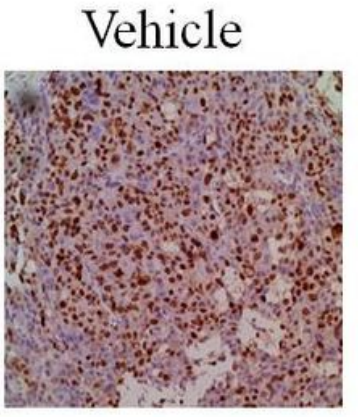

GW3965

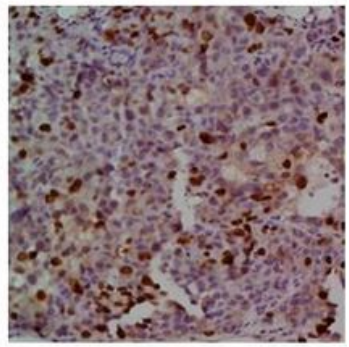

d

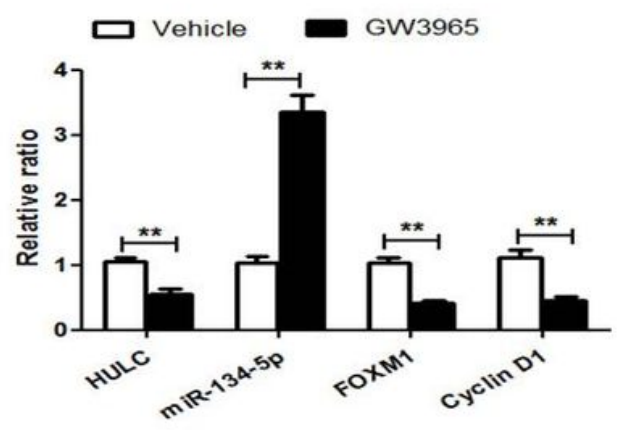

$\mathrm{e}$

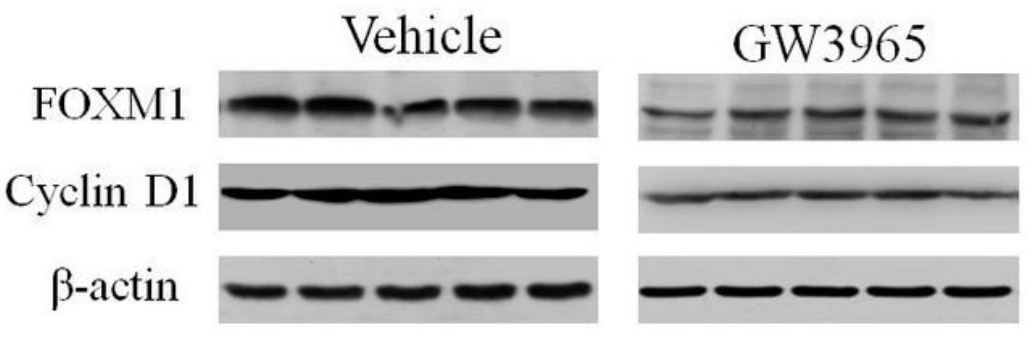

\section{Figure 7}

Activation of LXR suppresses the growth of HCC xenografts and regulates the HULC/miR-134-5p/FOXM1 axis in vivo. a, b A total of $5 \times 106$ Hep3B cells were subcutaneously injected into the right axilla of each male nude mouse. When palpable tumors were formed, the mice were randomly assigned to control and test groups ( $n=5$ per group). The control group was received a daily intraperitoneal injection with vehicle control soyabean oil for 12 days, while the test group was received the same treatment with LXR agonist GW3965 $(30 \mathrm{mg} / \mathrm{kg})$. Then the mice were sacrificed and the volumes of the harvested xenograft tumors were measured using the formula: volume $=$ width $2 \times$ length $\times 1 / 2(a)$, while the xenografts were photographed (b). c The expression of Ki67 (a marker of cell proliferation) in the HCC xenografts was examined by immunohistochemical staining. $d$ The expression of HULC, miR-134-5p, FOXM1 and cyclin D1 in the HCC xenografts was examined by qPCR. e The protein levels of FOXM1 and cyclin D1 in the HCC xenografts were detected by Western blot. $* * P<0.01, * \star * P<0.001$. 